\title{
Cognitive Deficits in Huntington's Disease: Insights from Animal Models
}

\author{
Elizabeth A. Wang $\cdot$ Carlos Cepeda $\cdot$ Michael S. Levine
}

Published online: 17 January 2012

(C) Springer Science+Business Media, LLC 2012

\begin{abstract}
Although Huntington's disease (HD) is commonly recognized as a movement disorder, cognitive dysfunction is an intrinsic feature of the disease that often manifests before the onset of chorea. Neuronal loss has been demonstrated in anatomical regions known to be substrates of learning and memory, but cell loss is presaged by functional alterations. Changes in long-term synaptic plasticity, a substrate of memory processes, emerge in cognitive domains such as the hippocampus, the cortex, and the striatum. Insights from animal models provide mechanistic explanations of how long-term synaptic plasticity is altered in these regions. Glutamate and dopamine receptors play a crucial role in such changes and progress in this area of investigation has made significant strides in recent years. Based on these discoveries, novel therapies are being developed to improve clinical outcomes and ameliorate cognitive symptoms of HD.
\end{abstract}

Keywords Animals models · Huntington's disease · Synaptic plasticity Cognition · Long-term potentiation . Long-term depression $\cdot \mathrm{N}$-methyl-D-aspartate receptor . Dopamine $\cdot$ Metabolic mapping $\cdot$ Hippocampus $\cdot$ Cerebral cortex $\cdot$ Thalamus $\cdot$ Striatum $\cdot$ Aging

\section{Introduction}

Huntington's disease (HD) is a fatal, dominantly inherited neurodegenerative disorder caused by an unstable expansion

E. A. Wang $\cdot$ C. Cepeda $(\bowtie) \cdot$ M. S. Levine

Intellectual and Developmental Disabilities Research Center,

Semel Institute for Neuroscience and Human Behavior, David

Geffen School of Medicine, University of California Los Angeles,

760 Westwood Plaza,

Los Angeles, CA 90095, USA

e-mail: ccepeda@mednet.ucla.edu of a polymorphic trinucleotide repeat sequence (CAGn) in the HTT gene, which encodes the huntingtin $(\mathrm{Htt})$ protein [1]. These repeat sequences translate into an elongated stretch of glutamine near the Htt amino terminus, conferring toxic functions to mutant $\mathrm{Htt}(\mathrm{mHtt})$, ultimately leading to neurodegeneration [1]. Htt is a large, highly conserved protein that is ubiquitously expressed throughout the body [2]. Although its exact function remains unclear, $\mathrm{Htt}$ is a membrane-associated protein involved in axonal trafficking [3].

Clinically, the consequences of $\mathrm{mHtt}$ expression are farreaching and physically and mentally devastating. Typical HD onset occurs between ages 30-50 years. Progressive physical and mental deterioration occur over the next 15 25 years before these effects become lethal. Clinical presentations of HD include progressive motor dysfunction manifested as chorea, mood disorders, and cognitive deficits [4]. A juvenile form of HD also occurs, generally when the length of CAG repeats is greater than 60. Patients develop spasticity, epileptic seizures, and intellectual decline associated with a more rapidly progressing course [5].

Deficits in cognition are an integral feature of HD and manifest early in the course of the disease [6]. Although the neuropathological hallmark of HD is the selective degeneration of GABAergic striatal medium-sized spiny neurons (MSNs), neuronal loss has been observed in other regions of the brain such as the cerebral cortex, thalamus, hypothalamus, globus pallidus, hippocampus, and cerebellum [7, 8•, 9-11], suggesting that integration and transfer of information throughout the brain is altered in HD.

It is important to both correlate cognitive deterioration with the specific neuropathology of HD and identify the ways these processes are disrupted. This review describes the main cognitive deficits associated with $\mathrm{HD}$, not only in humans but also in genetic rodent models, which have provided important insights into progression and mechanisms of brain dysfunction [12], 
and discusses possible mechanisms of cognitive deficits and promising treatments.

Cognitive Processes Subserved by the Hippocampus, Striatum, Thalamus and Cerebral Cortex

In the study of cognition, cortical and subcortical structures have become areas of extensive investigation. The basal ganglia, cerebral cortex, hippocampus, and thalamus are recognized as key anatomical substrates of cognitive processes such as attention, executive function, learning, and memory [13], processes that are not unitary in nature but rather supported by relatively independent neural systems that differ in the cognitive aspect they facilitate [14]. For example, learning tasks require the concurrent activation of multiple and parallel memory systems. Although these systems operate semi-independently, their interactions do ultimately give rise to the apparently seamless control of cognition and behavior [15].

While the hippocampus is known as the site of place learning, the striatum is engaged by repetitive stimulusresponse associations [16]. These systems do not act independently but cooperatively and competitively, thus managing responses needed in complex behavioral tasks [16]. Damage inflicted onto either of the two systems not only leads to changes in behavior, but also affects the influence exerted by the other in cognitive processes [14]. Interactions between the hippocampus and prefrontal cortex also support both working and long-term memory [17]. The neocortex in particular is believed to be the permanent repository of memory [15] and the hippocampus the site of encoding and retrieving short-term memory [18]. Connectivity among these sites gives rise to the hippocampo-fronto-striatal circuit, important for higher cognitive tasks such as goaldirected behavior and executive function, cognitive processes considered to be at the pinnacle of human cognition [19].

Similarly, the frontostriatal circuits form a distributed neuronal system involved in learning tasks and executive function. While the caudate nucleus initiates and maintains adaptive responses, the prefrontal cortex is centrally involved in monitoring performance and selecting strategies [20]. The dorsolateral striatum, in particular, is implicated in procedural learning [21]. The thalamus is also functionally important in the integration and transference of information between striatum and cortex [22]. It is a critical region subserving attentional processes and behavioral switching [23]. In particular, the thalamostriatal pathway is becoming the focus of intense research in humans and animal models [24]. Human studies have demonstrated adverse cognitive consequences of thalamic damage in executive tests $[25$, 26]. The functional connectivity between these cortical and subcortical areas manifests in what is recognized as the basal ganglia-thalamo-cortical circuit [22].
Cognitive Deficits in Human Huntington's Disease

Impaired attention, visuospatial skills, and mnemonic function can be observed during prodromal HD [27]. Later, patients with HD show impaired performance in executive tests requiring planning, problem solving, stimulus-response selectivity, and concept formation [28, 29]. Although much remains to be understood about the neural correlates underlying cognitive dysfunction in HD, striatal, thalamic, and cortical atrophy, which are the most common pathological findings in patients with HD, could play a central role [30]. Structural and functional imaging studies have indeed correlated neuronal loss in these areas with impaired attention, sensory integration, executive functions, learning, and working memory $[25,31]$. However, it is now widely accepted that early cognitive deficits can occur in the absence of neural atrophy or overt motor symptoms, suggesting that cellular and synaptic activity in the thalamus and cortex could be altered before neuropathological changes become apparent $[7,9,32 \cdot \bullet]$. Studies have shown cognitive deficits in patients who are decades before motor diagnosis [32••]. These deficits affect functional skills and work performance [8•]. Prodromal deficits can be very specific; in HD carriers, before presentation of movement disorders, attentional set shifting and semantic verbal fluency are affected [27]. Further, in sensory tests that do not involve motor components, sensory-evoked brain activation is reduced in cortical and subcortical areas [31]. Electroencephalographic studies have shown that the most consistent abnormality in patients with HD is suppression of $\alpha$-activity. Suppression of the $\alpha$-rhythm points to thalamic abnormalities [33] and is consistent with anatomical changes in preclinical HD [30].

Imaging studies have demonstrated abnormalities in brain metabolism and network organization, characterized by metabolic decreases in the caudate and lentiform nuclei and the mesial temporal cortex, and an early increase followed by a decrease in the thalamus [34]. Such instances of increased metabolic activity may reflect alterations in cellular function that presage metabolic failure and cell death [35]. Altered synaptic function via reduced plasticity also has been demonstrated in premanifest HD patients. Motor cortex plasticity in HD gene carriers is abnormal and not closely related to the development of the motor phenotype [36]. However, after clinical onset, reduced long-term plasticity in the motor cortex seems to accompany the motor phenotype [37]. The HD motor cortex also shows depressed excitability [38].

While clinical studies in HD patients have revealed that cognitive changes precede motor symptoms, mechanistic studies are difficult to perform. Animal models of HD have become an important tool to understand the progression of HD symptoms. In particular, genetic models carrying the mutated human transgene replicate most HD symptoms and permit mechanistic examination [12]. 


\section{Animal Models of Huntington's Disease}

Understanding how molecular, cellular, and synaptic signaling processes are disrupted in the pathogenesis of HD is integral to the study of behavioral and neuropathological changes. To this end, a large number of animal models have been created to evaluate at the mechanistic level how cell loss in the striatum induces the pathophysiology of HD. Because these models have been reviewed extensively [39•, 40, 41], this article provides a summary description of the models that have facilitated the study of mechanisms underlying cognitive alterations in HD.

Neurotoxin-based models were generally used before the discovery of the HD gene. Although they allowed for an examination of the mechanisms involved in cell death, and were instrumental for the development of the excitotoxicity hypothesis of HD [42], they did not enable a study of disease progression or the differential vulnerability of neurons that are known to degenerate in HD. This is important because although the hallmark of HD is the loss of MSNs, studies in animal models and humans have demonstrated that neuronal dysfunction occurs in the absence of neurodegeneration and may be the cause of cognitive symptoms seen in early $\operatorname{HD}[12$, 43]. Toxin models are based on the idea that striatal lesions can be induced chemically in a way that reproduces neuropathology (i.e., selective degeneration of projection MSNs but relative sparing of interneurons and fiber tracts). Early studies suggested that injections of the excitotoxin kainic acid produce a phenotype resembling the neuropathology of $\mathrm{HD}$ (for a review see [44]). Later, this model was refined through use of quinolinic acid, an $N$-methyl-D-aspartate (NMDA)-type excitotoxin. Another model, the 3-nitropropionic acid (3-NP) model of $\mathrm{HD}$, is created by exposure to a mitochondrial toxin. Infusion of 3-NP leads to selective striatal lesions that reproduce most of the pathophysiological hallmarks of HD, including striatal atrophy and cognitive disorders [45].

The discovery of the gene responsible for HD enabled the study of mechanisms and disease progression through genetic animal models carrying the defective gene. The most currently used models include fragment, full-length, and knock-in models. These models differ in CAG repeat length, copy numbers, and transgene expression levels. R6/2 mice expressing exon 1 with about $150 \mathrm{CAG}$ repeats manifest a very rapidly progressing phenotype, similar to the juvenile form of HD in humans. Symptomatic animals display overt behavioral alterations as early as 5-6 weeks of age, including hind limb clasping, weight loss, and death at about 15 weeks [46]. Pathological alterations include the formation of nuclear inclusions [47], which can be observed in the presymptomatic stage, particularly in the striatum and the CA1 region of the hippocampus [48]. There also are changes in glutamate and dopamine (DA) receptors [49, 50]. Many of these alterations are correlated with learning impairments on a number of cognitive tasks [51]. Another line, the R6/1 (with about 110 CAG repeats), presents with similar phenotypic alterations as the R6/2 but in a more protracted form [46]. Weight loss and clasping can be observed at 19-23 weeks and become more pronounced with age. The first transgenic rat model, the tgHD, carries $51 \mathrm{CAG}$ repeats [52]. An advantage of this model is that it concomitantly expresses cognitive, emotional, and motor disturbances, spatially localized inclusions, as well as striatal cell death $[52,53]$.

The most widely studied full-length mouse model uses the yeast artificial chromosome (YAC) expressing normal (YAC18) and mutant (YAC46, YAC72, and YAC128) human $\mathrm{Htt}[54,55]$. YAC72 mice display abnormal behavior around age 7 months, as well as selective degeneration of MSNs in the lateral striatum by 12 months. YAC128 mice display alterations similar to YAC72 mice, but these alterations are more severe and occur earlier [55]. These mice exhibit increased open field activity at about 3 months and rotarod performance deficits starting at 6 months [55]. Similar to human $\mathrm{HD}$, cognitive dysfunction and mood disturbance precede motor abnormalities [56]. In addition, significant and selective atrophy and neuronal loss occur in the striatum and cortex of YAC128 mice $[55,56]$.

The major advantage of knock-in models is that they express full-length $\mathrm{mHtt}$ in its native genomic context. Several models that differ mainly in the number of CAG repeats (from 48-200) have been generated [57-61]. In knock-in models overt behavioral changes are often subtle, but careful testing demonstrates abnormalities as early as ages 12 months [62]. A more severe phenotype develops as the mice age beyond 1 year [63]. A consistent feature of knockin mice is the presence of nuclear staining and microaggregates very early in the course of the disease [63]. By contrast, nuclear inclusions are observed only in older mice [62], and loss of MSNs occurs at about 2 years [63].

\section{Cognitive Alterations in Mouse Models of Huntington's Disease}

Long-lasting changes in the efficacy of excitatory transmission have been proposed to represent the cellular basis of cognitive processes such as learning and memory. Insights from animal models of HD have helped our understanding of how synaptic plasticity is altered in the hippocampus, cerebral cortex, and striatum. The following sections examine cognitive alterations in HD animal models in the context of two forms of synaptic plasticity: long-term potentiation (LTP) and long-term depression (LTD).

\section{Synaptic Plasticity in Hippocampus}

Early investigations of synaptic plasticity in HD animal models concentrated on the hippocampus, using electrophysiology 
in brain slices. One of the first studies examined spatial cognition and the ability of CA1 and dentate granule cell synapses to support plasticity in the R6/2 transgenic mouse, using high-frequency stimulation (HFS) and low-frequency stimulation (LFS) to induce LTP and LTD, respectively [64]. LTP is reduced at transgenic synapses, and LFS results in activity-dependent synaptic depression not seen in control slices. Thus, transgenic slices show an impaired ability to sustain long-term excitatory neurotransmission. Spatial cognition, a hippocampal-dependent process, similarly is impaired before the onset of an overt phenotype, suggesting that altered plasticity contributes to the prodromal cognitive symptoms reported in HD gene carriers. Similarly, LTP is not induced in CA1 neurons in 10-month-old YAC46 and YAC72 mice [54]. In fact, HFS induced depression instead of potentiation. Thus, hippocampal synapses in HD seem to be compromised in their ability to respond to intense synaptic demand, leading to impairments of LTP.

LTP in the CA3 region of the hippocampus, the source of mossy fiber (MF) input thought to be important in initiating learning, is also selectively impaired in presymptomatic R6/ 2 mice [65]. Deficits in MF LTP may be attributed to early changes in complexin II expression, a presynaptic protein that is among the first to dysregulate in R6/2 neurons. As in controls, LTD in mutant mice shows developmentally controlled downregulation, declining by early adulthood [66]. However, at 3-4 months, this process is markedly altered with a re-emergence of LFS-induced depression weeks before the appearance of an overt phenotype.

These findings suggest that a tendency towards LTP reduction and LTD augmentation in hippocampus underlies cognitive impairments in early HD. Altered hippocampal plasticity invariably occurs before an overt behavioral phenotype, supporting the idea that cellular and synaptic alterations in cognitively important regions may precipitate the cognitive deficits that appear in early HD and worsen as the disease progresses.

\section{Synaptic Plasticity in Cerebral Cortex}

In mouse models of HD, alterations in synaptic plasticity have been identified in three major cortical areas: the barrel cortex, the perirhinal cortex, and the medial prefrontal cortex. The barrel cortex displays deficits in learning-dependent plasticity in presymptomatic R6/1 mice [67]. Such deficits correlate with an impairment of somatosensory-discrimination learning ability [68]. In this study, whisker-deprived wild-type mice show an experience-dependent expansion of the functional representation of the spared row of whiskers, a process that involves potentiation of responses to spared vibrissae and, possibly, LTP/LTD-like mechanisms [69]. In presymptomatic R6/1 mice, this expansion failed to occur, supporting the view that aberrations in cortical plasticity emerge before a motor phenotype and may contribute to impairments in learning and memory processes seen in human HD.

Electrophysiological studies in the perirhinal cortex also lend support to this view. Perirhinal synapses in the R6/1 mouse model show age-dependent impairments in LTD [70, 71]. Namely, there is an age-dependent derailment of LTD expression in transgenic slices, in which LTD is augmented at age 2 months, reversed at 5 months, and then reduced until becoming crucially absent from ages 7-9 months. The most recent evidence that plastic events in the neocortex are altered in the presence of the HD transgene comes from a study showing that LTP induction is impaired in the medial prefrontal cortex of presymptomatic R6/1-89Q and symptomatic R6/ 1-116Q mice [72••]. The magnitude of this impairment correlates with the size of the CAG repeat, showing that a progressive derailment in the LTP inductive mechanism is one defining feature of the HD disease trajectory.

The cortex in transgenic mice thus shows a general trend towards compromised LTP and LTD, correlating with impairments in learning-dependent behavioral tasks. The cortex of transgenic mice, at least at the initial stages of the disease, shares with the mutant hippocampus similar features of impaired LTP and augmented LTD.

\section{Synaptic Plasticity in Striatum}

Alterations in striatal plasticity in HD are much less known, although implications have been drawn from mouse model studies noting perturbed excitatory synaptic transmission and DA function [73-75]. Nonetheless, R6/2 mice, tgHD rats, and the 3-NP model of HD have been studied in the context of LTP and LTD.

Consistent with the idea that LTP processes derail in HD, MSNs from presymptomatic R6/2 mice at age 6 weeks show no deficits in LTP [45], while those at age 8 weeks and older do [76]. Meanwhile, LTD in the adult R6/2 corticostriatal pathway appears to be maintained [76]. Alternatively, 3-NP rats show normal LTP but abnormal synaptic depotentiation [45] and suppressed LTD compared to controls [77]. A loss in synaptic depotentiation, a form of synaptic plasticity involved in mechanisms of "forgetting" and increasing information storage capacity, has been shown in 3-NP rats [78]. Together, this suggests a relationship between sustained excitatory synaptic transmission and MSN cell death.

When evoked by stimulation of the prelimbic cortex, field potentials in the dorsomedial striatum of the tgHD rat at a presymptomatic stage show enhanced LTP [79•]. That these aberrations in plasticity occur in conjunction with poorer temporal sensitivity suggests that normal plasticity at prefrontalstriatal circuits is required for proper timing behavior.

Taken together, R6/2, $\operatorname{tgHD}$, and 3-NP models fail to agree on the direction in which LTP and LTD are altered in striatum, and this dissimilarity may be a matter of different animal 
models, stimulation parameters, or induction techniques. Additionally, these studies failed to separate MSNs of the direct and indirect pathways through fluorescent protein labeling, and this may also account for inconsistencies. Nonetheless, the outcomes indicate that alterations in striatal plastic events are part of the HD pathology. Thus, these studies are working toward a more cohesive understanding of how striatal neurons are compromised in their capacity to process learning and taskrelated information and contribute to cognitive deficits in HD.

\section{Mechanisms of Cognitive Dysfunction in Huntington's Disease}

Interactions between glutamate and DA receptors are vital to numerous cognitive functions, such as learning and memory, motor coordination, and reward mechanisms [80-83]. Alterations in NMDA (NMDAR) and DA receptors also play a crucial role in mediating aberrant synaptic plasticity in HD models. Indeed, the R6/2 striatum shows deficits in DA release and DA receptor expression [49, 75, 84]. Because LTP is dependent on NMDA and D1 receptor activation, disruptions in one or both systems may be responsible for impairments in plasticity [76].

\section{Role of NMDA Receptors}

Physiologically, the NMDAR triggers learning-related plasticity by inducing LTP and LTD [85]. While these forms of plasticity provide insights into network function, they are mechanistically limited. Unlike long-lasting forms of plasticity, short-term plasticity is involved in the dynamic, moment-to-moment adjustment of synaptic strength during the processing of neural information, occurring on the order of seconds to minutes [86]. Activity-dependent short-term plasticity includes paired-pulse facilitation, paired-pulse depression, and post-tetanic potentiation (PTP). Electrophysiological protocols testing short-term plasticity offer a better glimpse into mechanisms of synaptic dysfunction in HD.

At CA1 hippocampal and cortical synapses, PTP is reduced in transgenic slices $[64,72 \bullet \bullet$. PTP is believed to indicate presynaptic function, reflecting a period of enhanced neurotransmitter release caused by loading the presynaptic terminal with calcium ions. Although an earlier hippocampal study in a knock-in mouse also observed reduced PTP, citing a deficit in neurotransmitter mobilization as the cause [87], blocking LTP induction with an NMDAR antagonist produced similar PTP in control and transgenic mice, suggesting that altered mechanisms associated with the NMDAR itself are responsible for deficits in synaptic plasticity [64].

That hippocampal slices from 6-month-old mutant mice show NMDAR-dependent hyperexcitability suggests that altered NMDAR function in transgenic mice gives rise to early electrophysiological abnormalities presaging altered plasticity in older animals [54]. These slices show increased baseline NMDAR function, which would cause elevated influx of calcium during normal synaptic transmission. Indeed, neurons from 10-month-old mutant mice show higher resting levels of intracellular calcium [54]. The lack of LTP at CA1 pyramidal synapses may thus be caused by NMDAR inactivation in response to elevated calcium influx during HFS. In addition, NMDARdependent LTD is maintained in the R6/2 striatum even though NMDAR-dependent LTP is compromised, suggesting that NMDAR impairment in the presence of mHtt may only be partial in nature, leading to selective deficits in plasticity [76].

That the YAC mutant hippocampus shows hyperexcitability and increased NMDAR-mediated basal synaptic transmission before demonstrating deficits in LTP [54] led to a speculation that differential expression of the NR2B NMDAR subunit may be a cause, because injection of $\mathrm{mHtt}$ into cells with functional NMDARs induces a selective augmentation of currents in NR2B-containing NMDARs [88]. This brings up an interesting but controversial debate on the contribution of individual NMDAR subunits to NMDAR-mediated currents that strengthen excitatory synapses. Although activation of NR2B-containing NMDARs is generally viewed as excitotoxic, NR2 subunit expression varies based on receptor location, with NR2A-containing NMDARs predominating at synaptic sites and NR2Bcontaining NMDARs at both synaptic and extrasynaptic receptor locations [89]. Synaptic sites are the locus of plastic events, and thus NR2B-containing NMDARs may play an equal role in mediating plasticity. For instance, blockade of NR2B-containing NMDARs blocks D1 potentiation of NMDA currents [89].

Alterations in NMDAR function in HD are complex and have only begun to be elucidated. Overall, NMDAR contributions to synaptic plasticity seem to require a balancing act between not only NR2A- and NR2B-containing NMDARs, but also between NMDAR over- and under-activation. Strategies aimed at moderating NMDA receptor activity may ultimately lead to a re-normalization in synaptic plasticity and cognitive function.

\section{Role of Dopamine}

The strength of synaptic transmission can be remodeled by neuromodulators such as DA [90]. DA receptors are also involved in the induction and maintenance of LTP [91, 92], working in tandem with the glutamatergic system. Early cognitive decline also has been correlated with striatal and cortical loss of DA receptors in presymptomatic and earlystage HD patients [93].

In genetic HD models, DA receptor activation is crucially reduced, giving rise to deficits in synaptic plasticity. For example, symptomatic R6/1 mice are deficient in the ability 
to support LTD and there is evidence that this may be due a pathological reduction in D2 receptor activation [71]. Cortical transgenic slices show aberrations in paired-pulse profiles, indicative of short-term plasticity. Instead of exhibiting paired-pulse depression like controls, mutants exhibit a more facilitatory profile, indicating a change in neuromodulation. Antagonism of D2 receptors in control slices produces this facilitatory profile, while exposure to quinpirole, a D2 receptor agonist, not only produces a less facilitatory profile that resembles age-matched controls, but also restores the ability of transgenic slices to support LTD.

Additionally, striatal LTD in R6/2 mice shows a variable dependence on D1 receptors, implying that these receptors are not required for weakening striatal synapses [76]. Alternatively, that LTP fails in the cortex might reflect a higher threshold for LTP induction, a phenomenon that may be amenable to D1 receptor modulation [72••]. That impaired LTD in the perirhinal cortex can be reversed in the presence of a D2 receptor agonist is consistent with the finding that impaired LTP in the medial prefrontal cortex can be reversed in the presence of a D1 receptor agonist $[72 \bullet \cdot]$. LTP in the prefrontal cortex is in fact largely dependent on the activation of D1 receptors [94]. Together, this suggests that dysfunction in DA signaling is an underlying feature of early cognitive decline in HD.

\section{Treatments and Promising Therapeutics}

Although HD is thus far thought to be incurable, various therapies have been used to reduce or delay symptoms. In humans, cognitive-enhancing drugs such as memantine, rivastigmine, and donepezil have shown modest benefit, and DA depleters such as tetrabenazine can reduce chorea [95]. Treatment for HD is limited and exclusively symptomatic. However, the following emerging therapeutic strategies have shown promise experimentally and/or clinically.

\section{Brain-Derived Neurotrophic Factor}

Brain-derived neurotrophic factor (BDNF) may rescue pathologies in synaptic plasticity and has emerged as a promising therapeutic candidate for its positive effects on excitatory synaptic function. Although studies on LTP and LTD in genetic mouse models have generally implicated a role for altered NMDA and DA function, alterations also may be mediated by pathological decreases in BDNF observable even at the presymptomatic stage [96]. BDNF is particularly relevant to the corticostriatal pathway in mutant mouse models. MSNs do not produce BDNF but rely on anterograde transfer from the cortex, a process perturbed by $\mathrm{mHtt}$ [97]. BDNF is co-released with glutamate in the corticostriatal pathway [98] and promotes LTP in striatal MSNs, likely through enhancing NMDA currents [99]. An emerging theme is that BDNF also plays a role in regulating synaptic plasticity in hippocampus and cortex [100]. In HD knock-in mice, BDNF has been shown to rescue impaired LTP in hippocampal slices [101] and modulate higher-order cognitive processes in different learning tasks even before the onset of motor symptoms [102]. Thus, BDNF is one strategy that can target cognitive difficulties before an overt motor phenotype emerges.

\section{Ampakines}

Upregulating endogenous BDNF levels through treatment with ampakines, a class of drugs that positively modulate $\alpha$-amino-3-hydroxy-5-methyl-4-isoxazolepropionic acid (AMPA)-type glutamate receptors, may rescue the HD synaptic and cognitive phenotype [103•]. In 16-week-old HD mice, ampakine treatments work selectively, offsetting impairments in long-term memory without measurable effects on impaired locomotor activity. Because ampakine treatments are well tolerated in clinical trials and require only brief exposures to be effective, ampakines represent a novel strategy for the chronic treatment of cognitive deficits seen in early HD [104].

\section{Environmental Enrichment}

Proof-of-concept studies have shown that spatial memory deficits in HD mice can be ameliorated by environmental enrichment through altering synaptic composition [105] and increasing BDNF expression in cognitively important areas such as the hippocampus [106]. Environmental enrichment may enhance experience-dependent plasticity by inducing subtle, region-specific effects on dendritic morphology and spine density that can contribute to strengthening synaptic connections [107]. This has proven effective in symptomatic R6/1 mice housed in an enriched environment, which showed neuronal morphological changes that could underlie some of the beneficial effects of enrichment [108, 109].

\section{Memantine}

Antagonism of NMDARs is a therapeutic strategy used to reduce progression of HD pathology and phenotype because NMDARs, when overactivated, produce neuronal damage. Although still speculative, increased basal NMDAR function, by elevating intracellular calcium levels, can impede LTP [54]. Although memantine, an NMDAR antagonist, has not been specifically shown to ameliorate the plastic phenotype of HD, therapeutic concentrations can effectively block excessive extrasynaptic NMDAR-mediated currents, while relatively sparing normal synaptic activity [110••, 111]. In blocking excitotoxic cell death, memantine has been shown to slow the progression of HD neuropathology and the cognitive phenotype by reducing striatal cell death [112] 
and improving the performance of mutant mice on a motor learning task [110].

\section{Dopamine Agonists}

There is much promise in therapeutics that take advantage of DA modulation of plasticity because there is evidence that D2 receptor agonists can rescue impaired LTD and D1 receptor agonists can rescue impaired LTP [71, 72••]. However, preliminary results testing a D2 receptor partial agonist, aripiprazole, on HD patients suggest that the drug can improve chorea and depression, but not cognitive function [113]. Similarly, case studies have demonstrated that the drug only modestly improves cognitive deficits [114]. Thus, while experimental outcomes have been promising, the role of DA agonists in ameliorating the HD cognitive phenotype remains to be explored further at the clinical level.

\section{Conclusions}

Although HD is commonly seen as a movement disorder characterized by neostriatal pathology, the clinical phenotype of HD has far-reaching and devastating consequences on cognitive function involving multiple neuronal systems. Cognitive deficits in HD have complex origins arising from not only neuronal atrophy and aberrant metabolic activity in cognitively important regions, but also alterations in synaptic plasticity, often occurring before the neuropathology or motor symptomatology become apparent. Insights from animal models have led to a better understanding of the mechanisms underlying altered synaptic plasticity in HD. NMDA and DA receptors have emerged as mechanistically relevant targets in the search for therapeutics, and progress in this area of research has led to novel treatment strategies for ameliorating cognitive dysfunction in HD.

Acknowledgements This work was supported in part by United States Public Health Service (USPHS) grant NS 41574 and a contract with the CHDI Foundation, Inc.

\section{References}

Papers of particular interest, published recently, have been highlighted as:

- Of importance

-. Of major importance

1. The Huntington's Disease Collaborative Research Group. A novel gene containing a trinucleotide repeat that is expanded and unstable on Huntington's disease chromosomes. Cell. 1993;72: 971-83.
2. Strong TV, Tagle DA, Valdes JM, et al. Widespread expression of the human and rat Huntington's disease gene in brain and nonneural tissues. Nat Genet. 1993;5:259-65.

3. Truant R, Atwal R, Burtnik A. Hypothesis: Huntingtin may function in membrane association and vesicular trafficking. Biochem Cell Biol. 2006;84:912-7.

4. Harper PS, Jones L. Huntington's disease: Genetic and molecular studies. In: Bates GP, Harper PS, Jones L, editors. Huntington's disease. 3rd ed. Oxford: Oxford University Press; 2002. p. 11358 .

5. Telenius H, Kremer HP, Theilmann J, et al. Molecular analysis of juvenile Huntington disease: the major influence on (CAG)n repeat length is the sex of the affected parent. Hum Mol Genet. 1993;2:1535-40.

6 . Brandt J, Butters N. The neuropsychology of Huntington's disease. Trends Neurosci. 1986;9:118-20.

7. Beglinger LJ, Nopoulos PC, Jorge RE, et al. White matter volume and cognitive dysfunction in early Huntington's disease. Cogn Behav Neurol. 2005;18:102-7.

8. - Beglinger LJ, O'Rourke JJ, Wang C, Langbehn DR, Duff K, Paulsen JS. Earliest functional declines in Huntington disease. Psychiatry Res 2010;178:414-418. This is a comprehensive multicenter study to evaluate which features of Total Functional Capacity, a component of the Unified Huntington's Disease Rating Scale, show early decline in a group of at-risk participants who later phenoconverted to manifest $H D$.

9. Rosas HD, Hevelone ND, Zaleta AK, Greve DN, Salat DH, Fischl B. Regional cortical thinning in preclinical Huntington disease and its relationship to cognition. Neurology. 2005;65:745-7.

10. Ruocco HH, Bonilha L, Li LM, Lopes-Cendes I, Cendes F. Longitudinal analysis of regional grey matter loss in Huntington disease: effects of the length of the expanded CAG repeat. J Neurol Neurosurg Psychiatry. 2008;79:130-5.

11. Petersen A, Gil J, Maat-Schieman ML, et al. Orexin loss in Huntington's disease. Hum Mol Genet. 2005;14:39-47.

12. Levine MS, Cepeda C, Hickey MA, Fleming SM, Chesselet MF. Genetic mouse models of Huntington's and Parkinson's diseases: illuminating but imperfect. Trends Neurosci. 2004;27:691-7.

13. Graybiel AM. Building action repertoires: memory and learning functions of the basal ganglia. Curr Opin Neurobiol. 1995;5:73341.

14. Poldrack RA, Packard MG. Competition among multiple memory systems: converging evidence from animal and human brain studies. Neuropsychologia. 2003;41:245-51.

15. Wang SH, Morris RG. Hippocampal-neocortical interactions in memory formation, consolidation, and reconsolidation. Annu Rev Psychol. 2010;61(49-79):C41-4.

16. Ciamei A, Morton AJ. Progressive imbalance in the interaction between spatial and procedural memory systems in the R6/2 mouse model of Huntington's disease. Neurobiol Learn Mem. 2009;92:417-28.

17. Cohen MX. Hippocampal-prefrontal connectivity predicts midfrontal oscillations and long-term memory performance. Curr Biol. 2011;21:1900-5.

18. Kumaran D. Short-term memory and the human hippocampus. J Neurosci. 2008;28:3837-8.

19. Thierry AM, Gioanni Y, Degenetais E, Glowinski J. Hippocampo-prefrontal cortex pathway: anatomical and electrophysiological characteristics. Hippocampus. 2000;10:411-9.

20. Grahn JA, Parkinson JA, Owen AM. The cognitive functions of the caudate nucleus. Prog Neurobiol. 2008;86:141-55.

21. Packard MG, Knowlton BJ. Learning and memory functions of the Basal Ganglia. Annu Rev Neurosci. 2002;25:563-93.

22. Haber S, McFarland NR. The place of the thalamus in frontal cortical-basal ganglia circuits. Neuroscientist. 2001;7:315-24. 
23. Kimura M, Minamimoto T, Matsumoto N, Hori Y. Monitoring and switching of cortico-basal ganglia loop functions by the thalamo-striatal system. Neurosci Res. 2004;48:355-60.

24. Ding J, Peterson JD, Surmeier DJ. Corticostriatal and thalamostriatal synapses have distinctive properties. J Neurosci. 2008;28: 6483-92.

25. Kassubek J, Juengling FD, Ecker D, Landwehrmeyer GB. Thalamic atrophy in Huntington's disease co-varies with cognitive performance: a morphometric MRI analysis. Cereb Cortex. 2005; 15:846-53.

26. Van der Werf YD, Scheltens P, Lindeboom J, Witter MP, Uylings HB, Jolles J. Deficits of memory, executive functioning and attention following infarction in the thalamus; a study of 22 cases with localised lesions. Neuropsychologia. 2003;41:1330-44.

27. Lawrence AD, Hodges JR, Rosser AE, et al. Evidence for specific cognitive deficits in preclinical Huntington's disease. Brain. 1998;121(Pt 7):1329-41.

28. Ho AK, Sahakian BJ, Brown RG, et al. Profile of cognitive progression in early Huntington's disease. Neurology. 2003;61:1702-6.

29. Peinemann A, Schuller S, Pohl C, Jahn T, Weindl A, Kassubek J. Executive dysfunction in early stages of Huntington's disease is associated with striatal and insular atrophy: a neuropsychological and voxel-based morphometric study. J Neurol Sci. 2005;239:11-9.

30. Wolf RC, Vasic N, Schonfeldt-Lecuona C, Ecker D, Landwehrmeyer GB. Cortical dysfunction in patients with Huntington's disease during working memory performance. Hum Brain Mapp. 2009;30:327-39.

31. Boecker H, Ceballos-Baumann A, Bartenstein P, et al. Sensory processing in Parkinson's and Huntington's disease: investigations with 3D H(2)(15)O-PET. Brain. 1999;122(Pt 9):1651-65.

32. •• Paulsen JS, Langbehn DR, Stout JC, et al. Detection of Huntington's disease decades before diagnosis: the Predict-HD study. J Neurol Neurosurg Psychiatry 2008;79:874-880. This interesting study uses genetic, neurobiological, and clinical markers to understand the early progression of HD in persons with a known gene mutation. Results indicate predictability from 1-2 decades before the point of traditional diagnosis.

33. de Tommaso M, De Carlo F, Difruscolo O, Massafra R, Sciruicchio V, Bellotti R. Detection of subclinical brain electrical activity changes in Huntington's disease using artificial neural networks. Clin Neurophysiol. 2003;114:1237-45.

34. Feigin A, Tang C, Ma Y, et al. Thalamic metabolism and symptom onset in preclinical Huntington's disease. Brain. 2007;130: 2858-67.

35. Eidelberg D, Surmeier DJ. Brain networks in Huntington disease. J Clin Invest. 2011;121:484-92.

36. Orth M, Schippling S, Schneider SA, et al. Abnormal motor cortex plasticity in premanifest and very early manifest Huntington disease. J Neurol Neurosurg Psychiatry. 2010;81:267-70.

37. Crupi D, Ghilardi MF, Mosiello C, Di Rocco A, Quartarone A, Battaglia F. Cortical and brainstem LTP-like plasticity in Huntington's disease. Brain Res Bull. 2008;75:107-14.

38. Lorenzano C, Dinapoli L, Gilio F, et al. Motor cortical excitability studied with repetitive transcranial magnetic stimulation in patients with Huntington's disease. Clin Neurophysiol. 2006;117:1677-81.

39. - Cepeda C, Cummings DM, Andre VM, Holley SM, Levine MS. Genetic mouse models of Huntington's disease: focus on electrophysiological mechanisms. ASN Neuro 2010;2:e00033. This recent review gives an in-depth summary and discussion on genetic models of HD from an electrophysiological perspective.

40. Milnerwood AJ, Raymond LA. Early synaptic pathophysiology in neurodegeneration: insights from Huntington's disease. Trends Neurosci. 2010;33:513-23.

41. Gil JM, Rego AC. The R6 lines of transgenic mice: a model for screening new therapies for Huntington's disease. Brain Res Rev. 2009;59:410-31.
42. DiFiglia M. Excitotoxic injury of the neostriatum: a model for Huntington's disease. Trends Neurosci. 1990;13:286-9.

43. Tobin AJ, Signer ER. Huntington's disease: the challenge for cell biologists. Trends Cell Biol. 2000;10:531-6.

44. Kim J, Bordiuk OL, Ferrante RJ. Experimental models of HD and reflection on therapeutic strategies. Int Rev Neurobiol. 2011;98:419 81.

45. Picconi B, Passino E, Sgobio C, et al. Plastic and behavioral abnormalities in experimental Huntington's disease: a crucial role for cholinergic interneurons. Neurobiol Dis. 2006;22:143-52.

46. Mangiarini L, Sathasivam K, Seller M, et al. Exon 1 of the HD gene with an expanded CAG repeat is sufficient to cause a progressive neurological phenotype in transgenic mice. Cell. 1996;87:493-506

47. Davies SW, Turmaine M, Cozens BA, et al. Formation of neuronal intranuclear inclusions underlies the neurological dysfunction in mice transgenic for the HD mutation. Cell. 1997;90:537-48.

48. Morton AJ, Lagan MA, Skepper JN, Dunnett SB. Progressive formation of inclusions in the striatum and hippocampus of mice transgenic for the human Huntington's disease mutation. J Neurocytol. 2000;29:679-702.

49. Ariano MA, Aronin N, Difiglia M, et al. Striatal neurochemical changes in transgenic models of Huntington's disease. J Neurosci Res. 2002;68:716-29.

50. Cha JH, Kosinski CM, Kerner JA, et al. Altered brain neurotransmitter receptors in transgenic mice expressing a portion of an abnormal human huntington disease gene. Proc Natl Acad Sci U S A. 1998;95:6480-5.

51. Lione LA, Carter RJ, Hunt MJ, Bates GP, Morton AJ, Dunnett SB. Selective discrimination learning impairments in mice expressing the human Huntington's disease mutation. J Neurosci. 1999;19:10428-37.

52. von Horsten S, Schmitt I, Nguyen HP, et al. Transgenic rat model of Huntington's disease. Hum Mol Genet. 2003;12:617-24.

53. Kantor O, Temel Y, Holzmann C, et al. Selective striatal neuron loss and alterations in behavior correlate with impaired striatal function in Huntington's disease transgenic rats. Neurobiol Dis. 2006;22:538-47.

54. Hodgson JG, Agopyan N, Gutekunst CA, et al. A YAC mouse model for Huntington's disease with full-length mutant huntingtin, cytoplasmic toxicity, and selective striatal neurodegeneration. Neuron. 1999;23:181-92.

55. Slow EJ, van Raamsdonk J, Rogers D, et al. Selective striatal neuronal loss in a YAC128 mouse model of Huntington disease. Hum Mol Genet. 2003;12:1555-67.

56. Van Raamsdonk JM, Murphy Z, Slow EJ, Leavitt BR, Hayden MR. Selective degeneration and nuclear localization of mutant huntingtin in the YAC128 mouse model of Huntington disease. Hum Mol Genet. 2005;14:3823-35.

57. Heng MY, Detloff PJ, Wang PL, Tsien JZ, Albin RL. In vivo evidence for NMDA receptor-mediated excitotoxicity in a murine genetic model of Huntington disease. J Neurosci. 2009;29:3200-5.

58. Levine MS, Klapstein GJ, Koppel A, et al. Enhanced sensitivity to $\mathrm{N}$-methyl-D-aspartate receptor activation in transgenic and knockin mouse models of Huntington's disease. J Neurosci Res. 1999;58:515-32.

59. Lin $\mathrm{CH}$, Tallaksen-Greene S, Chien WM, et al. Neurological abnormalities in a knock-in mouse model of Huntington's disease. Hum Mol Genet. 2001;10:137-44.

60. Shelbourne PF, Killeen N, Hevner RF, et al. A Huntington's disease CAG expansion at the murine Hdh locus is unstable and associated with behavioural abnormalities in mice. Hum Mol Genet. 1999;8:763-74.

61. Wheeler VC, White JK, Gutekunst CA, et al. Long glutamine tracts cause nuclear localization of a novel form of huntingtin in 
medium spiny striatal neurons in HdhQ92 and HdhQ111 knockin mice. Hum Mol Genet. 2000;9:503-13.

62. Menalled LB, Sison JD, Wu Y, et al. Early motor dysfunction and striosomal distribution of huntingtin microaggregates in Huntington's disease knock-in mice. J Neurosci. 2002;22:8266-76.

63. Hickey MA, Kosmalska A, Enayati J, et al. Extensive early motor and non-motor behavioral deficits are followed by striatal neuronal loss in knock-in Huntington's disease mice. Neuroscience. 2008;157:280-95.

64. Murphy KP, Carter RJ, Lione LA, et al. Abnormal synaptic plasticity and impaired spatial cognition in mice transgenic for exon 1 of the human Huntington's disease mutation. J Neurosci. 2000;20:5115-23.

65. Gibson HE, Reim K, Brose N, Morton AJ, Jones S. A similar impairment in CA3 mossy fibre LTP in the R6/2 mouse model of Huntington's disease and in the complexin II knockout mouse. Eur J Neurosci. 2005;22:1701-12.

66. Milnerwood AJ, Cummings DM, Dallerac GM, et al. Early development of aberrant synaptic plasticity in a mouse model of Huntington's disease. Hum Mol Genet. 2006;15:1690-703.

67. Cybulska-Klosowicz A, Mazarakis NK, Van Dellen A, Blakemore C, Hannan AJ, Kossut M. Impaired learning-dependent cortical plasticity in Huntington's disease transgenic mice. Neurobiol Dis. 2004; 17:427-34.

68. Mazarakis NK, Cybulska-Klosowicz A, Grote H, et al. Deficits in experience-dependent cortical plasticity and sensory-discrimination learning in presymptomatic Huntington's disease mice. J Neurosci. 2005;25:3059-66.

69. Fox K. Anatomical pathways and molecular mechanisms for plasticity in the barrel cortex. Neuroscience. 2002;111:799 814.

70. Cummings DM, Milnerwood AJ, Dallérac GM, Vatsavayai SC, Hirst MC, Murphy KPSJ. Abnormal Cortical Synaptic Plasticity in Mice Transgenic for Exon 1 of the Human Huntington's Disease Mutation. Brain Res Bul. 2007;72:103-7.

71. Cummings DM, Milnerwood AJ, Dallerac GM, et al. Aberrant cortical synaptic plasticity and dopaminergic dysfunction in a mouse model of huntington's disease. Hum Mol Genet. 2006;15:2856-68.

72. • Dallerac GM, Vatsavayai SC, Cummings DM, et al. Impaired long-term potentiation in the prefrontal cortex of Huntington's disease mouse models: rescue by D1 dopamine receptor activation. Neurodegener Dis 2011;8:230-239. This study implicates a role for aberrant D1 receptor activation in HD synaptic plasticity and is the first to suggest that D1 receptor agonists can rescue impairments in cortical LTP.

73. Andre VM, Cepeda C, Fisher YE, et al. Differential electrophysiological changes in striatal output neurons in Huntington's disease. J Neurosci. 2011;31:1170-82.

74. Cepeda C, Hurst RS, Calvert CR, et al. Transient and progressive electrophysiological alterations in the corticostriatal pathway in a mouse model of Huntington's disease. J Neurosci. 2003;23:961-9.

75. Johnson MA, Rajan V, Miller CE, Wightman RM. Dopamine release is severely compromised in the R6/2 mouse model of Huntington's disease. J Neurochem. 2006;97:737-46.

76. Kung VW, Hassam R, Morton AJ, Jones S. Dopamine-dependent long term potentiation in the dorsal striatum is reduced in the R6/2 mouse model of Huntington's disease. Neuroscience. 2007;146: 1571-80.

77. Dalbem A, Silveira CV, Pedroso MF, et al. Altered distribution of striatal activity-dependent synaptic plasticity in the 3-nitropropionic acid model of Huntington's disease. Brain Res. 2005;1047:148-58.

78. Picconi B, Centonze D, Hakansson K, et al. Loss of bidirectional striatal synaptic plasticity in L-DOPA-induced dyskinesia. Nat Neurosci. 2003;6:501-6.

79. - Hohn S, Dallerac G, Faure A, et al. Behavioral and in vivo electrophysiological evidence for presymptomatic alteration of prefrontostriatal processing in the transgenic rat model for huntington disease. J Neurosci 2011;31:8986-8997. This in vivo study provides behavioral correlates of altered synaptic plasticity in presymptomatic mutant rats, demonstrating that concomitant deficits in plasticity and timing behavior occur in premanifest $H D$.

80. Cepeda C, Levine MS. Dopamine and N-methyl-D-aspartate receptor interactions in the neostriatum. Dev Neurosci. 1998;20:1-18.

81. Calabresi P, Gubellini P, Centonze D, et al. Dopamine and cAMPregulated phosphoprotein $32 \mathrm{kDa}$ controls both striatal long-term depression and long-term potentiation, opposing forms of synaptic plasticity. J Neurosci. 2000;20:8443-51.

82. Schultz W. Dopamine signals for reward value and risk: basic and recent data. Behav Brain Funct. 2010;6:24.

83. Surmeier DJ, Ding J, Day M, Wang Z, Shen W. D1 and D2 dopamine-receptor modulation of striatal glutamatergic signaling in striatal medium spiny neurons. Trends Neurosci. 2007;30:228-35.

84. Hickey MA, Reynolds GP, Morton AJ. The role of dopamine in motor symptoms in the R6/2 transgenic mouse model of Huntington's disease. J Neurochem. 2002;81:46-59.

85. Collingridge GL, Isaac JT, Wang YT. Receptor trafficking and synaptic plasticity. Nat Rev Neurosci. 2004;5:952-62.

86. Reissner KJ, Pu L, Schaffhausen JH, et al. A novel postsynaptic mechanism for heterosynaptic sharing of short-term plasticity. J Neurosci. 2010;30:8797-806.

87. Usdin MT, Shelbourne PF, Myers RM, Madison DV. Impaired synaptic plasticity in mice carrying the Huntington's disease mutation. Hum Mol Genet. 1999;8:839-46.

88. Chen N, Luo T, Wellington C, et al. Subtype-specific enhancement of NMDA receptor currents by mutant huntingtin. J Neurochem. 1999;72:1890-8.

89. Jocoy EL, André VM, Cummings DM, et al. Dissecting the contribution of individual receptor subunits to the enhancement of N-methyl-D-aspartate currents by dopamine D1 receptor activation in striatum. Front Syst Neurosci. 2011;5:28.

90. Jay TM. Dopamine: a potential substrate for synaptic plasticity and memory mechanisms. Prog Neurobiol. 2003;69:375-90.

91. Blitzer RD, Wong T, Nouranifar R, Iyengar R, Landau EM. Postsynaptic cAMP pathway gates early LTP in hippocampal CA1 region. Neuron. 1995;15:1403-14.

92. Frey U, Huang YY, Kandel ER. Effects of cAMP simulate a late stage of LTP in hippocampal CA1 neurons. Science. 1993;260: 1661-4.

93. Pavese N, Andrews TC, Brooks DJ, et al. Progressive striatal and cortical dopamine receptor dysfunction in Huntington's disease: a PET study. Brain. 2003;126:1127-35.

94. Huang YY, Simpson E, Kellendonk C, Kandel ER. Genetic evidence for the bidirectional modulation of synaptic plasticity in the prefrontal cortex by D1 receptors. Proc Natl Acad Sci U S A. 2004;101:3236-41.

95. Paulson HL, Albin RL. Huntington's Disease: Clinical Features and Routes to Therapy. In: Lo DC, Hughes RE, eds. Neurobiology of Huntington's Disease: Applications to Drug Discovery (Chapter 1) Boca Raton (FL): CRC Press, 2011.

96. Zuccato C, Ciammola A, Rigamonti D, et al. Loss of huntingtinmediated BDNF gene transcription in Huntington's disease. Science. 2001;293:493-8.

97. Gauthier LR, Charrin BC, Borrell-Pages M, et al. Huntingtin controls neurotrophic support and survival of neurons by enhancing BDNF vesicular transport along microtubules. Cell. 2004;118: 127-38.

98. Zuccato C, Cattaneo E. Role of brain-derived neurotrophic factor in Huntington's disease. Prog Neurobiol. 2007;81:294-330.

99. Jia Y, Gall CM, Lynch G. Presynaptic BDNF promotes postsynaptic long-term potentiation in the dorsal striatum. J Neurosci. 2010;30:14440-5. 
100. Woo NH, Lu B. BDNF in Synaptic Plasticity and Memory. In: Squire LR, ed. Encyclopedia of Neuroscience. Oxford, 2009:135-143.

101. Lynch G, Kramar EA, Rex CS, et al. Brain-derived neurotrophic factor restores synaptic plasticity in a knock-in mouse model of Huntington's disease. J Neurosci. 2007;27:4424-34.

102. Giralt A, Rodrigo T, Martin ED, et al. Brain-derived neurotrophic factor modulates the severity of cognitive alterations induced by mutant huntingtin: involvement of phospholipaseCgamma activity and glutamate receptor expression. Neuroscience. 2009;158: $1234-50$.

103. - Simmons DA, Rex CS, Palmer L, et al. Up-regulating BDNF with an ampakine rescues synaptic plasticity and memory in Huntington's disease knockin mice. Proc Natl Acad Sci U S A 2009;106:4906-4911. Given that direct treatment with BDNF is not yet practical, this study gives proof-of-concept evidence that ampakine treatment can not only upregulate endogenous BDNF levels but also specifically target cognitive symptoms of $H D$.

104. Simmons DA, Mehta RA, Lauterborn JC, Gall CM, Lynch G. Brief ampakine treatments slow the progression of Huntington's disease phenotypes in R6/2 mice. Neurobiol Dis. 2011;41:436-44.

105. Nithianantharajah J, Barkus C, Murphy M, Hannan AJ. Geneenvironment interactions modulating cognitive function and molecular correlates of synaptic plasticity in Huntington's disease transgenic mice. Neurobiol Dis. 2008;29:490-504.

106. Zajac MS, Pang TY, Wong N, et al. Wheel running and environmental enrichment differentially modify exon-specific BDNF expression in the hippocampus of wild-type and pre-motor symptomatic male and female Huntington's disease mice. Hippocampus. 2010;20:621-36.

107. Nithianantharajah J, Barkus C, Vijiaratnam N, Clement O, Hannan AJ. Modeling brain reserve: experience-dependent neuronal plasticity in healthy and Huntington's disease transgenic mice. Am J Geriatr Psychiatry. 2009;17:196-209.

108. van Dellen A, Cordery PM, Spires TL, Blakemore C, Hannan AJ. Wheel running from a juvenile age delays onset of specific motor deficits but does not alter protein aggregate density in a mouse model of Huntington's disease. BMC Neurosci. 2008;9:34.

109. Laviola G, Hannan AJ, Macri S, Solinas M, Jaber M. Effects of enriched environment on animal models of neurodegenerative diseases and psychiatric disorders. Neurobiol Dis. 2008;31:159-68.

110. • Milnerwood AJ, Gladding CM, Pouladi MA, et al. Early increase in extrasynaptic NMDA receptor signaling and expression contributes to phenotype onset in Huntington's disease mice. Neuron 2010;65:178-190. Along with Okamoto et al. [111], these authors provide evidence of the important role of aberrant extrasynaptic NMDA receptor signaling in the HD phenotype, demonstrating the therapeutic potential of NMDA receptor antagonists such as memantine.

111. Okamoto S, Pouladi MA, Talantova M, et al. Balance between synaptic versus extrasynaptic NMDA receptor activity influences inclusions and neurotoxicity of mutant huntingtin. Nat Med. 2009;15:1407-13.

112. Lee ST, Chu K, Park JE, et al. Memantine reduces striatal cell death with decreasing calpain level in 3-nitropropionic model of Huntington's disease. Brain Res. 2006;1118:199-207.

113. Brusa L, Orlacchio A, Moschella V, Iani C, Bernardi G, Mercuri NB. Treatment of the symptoms of Huntington's disease: preliminary results comparing aripiprazole and tetrabenazine. Mov Disord. 2009;24:126-9.

114. Ciammola A, Sassone J, Colciago C, et al. Aripiprazole in the treatment of Huntington's disease: a case series. Neuropsychiatr Dis Treat. 2009;5:1-4. 